Check for updates

Cite this: RSC Adv., 2018, 8, 7765

\title{
Metabolism of five diterpenoid lactones from Dioscorea bulbifera tubers in zebrafish $\uparrow$
}

\author{
Wei Shi, (D) a Jie Ling, ${ }^{\mathrm{b}}$ Li-Long Jiang, ${ }^{\text {a }}$ Dong-Sheng Zhao, ${ }^{a}$ Ling-Li Wang, ${ }^{a}$ \\ Zi-Tian Wu, ${ }^{a}$ Ping Li, (D) ${ }^{a}$ Ying-Jie Wei ${ }^{\star b}$ and Hui-Jun Li (D) *a
}

Diterpenoid lactones (DLs) have been reported to be the main hepatotoxic constituents in Dioscorea bulbifera tubers (DBT), a traditional Chinese medicinal herb. The acquisition of early information regarding its metabolism is critical for evaluating the potential hepatotoxicity of DLs. We investigated, for the first time, the main metabolites of diosbulbin A (DIOA), diosbulbin C (DIOC), diosbulbin (DIOG), diosbulbin (DIOM) and diosbulbin (DIOF) in adult zebrafish. By using ultra-high performance liquid chromatographyquadrupole time-of-flight mass spectrometry (UHPLC-QTOF MS), 6, 2, 7, 5 and 4 metabolites of DIOA, DIOC, DIOF, DIOM and DIOG were identified in the zebrafish body and the aqueous solution, respectively. Both phase-I and phase-II metabolites were observed in the metabolic profiles and the metabolic pathways involved in hydroxyl reduction, glucuronidation, glutathione conjugation and sulfation. The above results indicated that hepatocytic metabolism might be the major route of clearance for DLs. This study provided important information for the understanding of the metabolism of DLs in DBT.

Received 30th November 2017 Accepted 12th February 2018

DOI: $10.1039 / c 7 r a 12910 f$

rsc.li/rsc-advances conjugates from EEA were detected both in vitro and in vivo. ${ }^{19}$ To fully understand the hepatotoxicity effects and mechanism of the DLs, it is essential to obtain early information regarding its metabolism. However, compared with extensive researches on DIOB and EEA, the knowledge of the metabolites and metabolic pathways focusing on other DLs are limited.

Due to the practical limitations of applying metabolism on human beings, animal models are of great importance in studying the metabolism of toxicants. In terms of the metabolism studies, rats are often chosen as the major object. ${ }^{20-22}$ With mammal-like genes, complex organ system and typical drug-metabolizing enzymes, the zebrafish model has proven to be a versatile tool for studying the metabolism of herbal components. ${ }^{23-26}$ Moreover, zebrafish-based metabolism studies have significant advantages of less amount of compound needed, lower cost, easier operation and higher efficiency. ${ }^{24,27}$ Owning to these distinguished characteristics, the zebrafish has become an important animal model and has provided new insights into metabolism studies.

In the present study, an ultra-high performance liquid chromatography-quadrupole time-of-flight mass spectrometry (UHPLC-QTOF MS) method was employed to characterize the metabolic profiles of DIOA, DIOC, DIOF, DIOG and DIOM in zebrafish biological samples. The metabolic pathways of these compounds and the fragmentation patterns of the metabolites were proposed.

\section{Experimental}

\section{Chemicals and materials}

The DBT was purchased from Yunnan province, China. The sample was authenticated by Prof. Hui-Jun Li and deposited at
Tongjia Lane, Nanjing 210009, China.E-mail: cpuli@163.com

${ }^{b}$ The Third Clinical School of Medicine, Nanjing University of Chinese Medicine, 100 Shizi Street, Nanjing 210028, China. E-mail:wyj970@163.com

$\dagger$ Electronic supplementary information (ESI) available. See DOI: 10.1039/c7ra12910f 


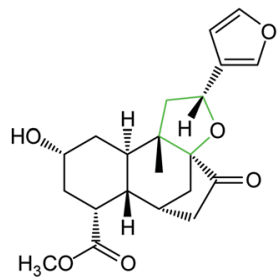

DIOA

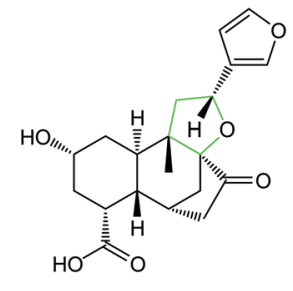

DIOC

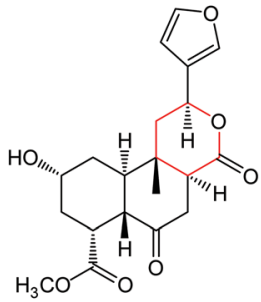

DIOF

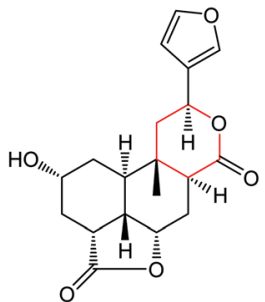

DIOG

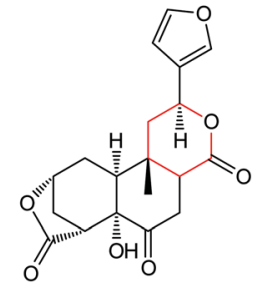

DIOM
Fig. 1 Chemical structures of DIOA, DIOC, DIOG, DIOF and DIOM.

State Key Laboratory of Natural Medicines (China Pharmaceutical University). Five DLs including DIOA, DIOC, DIOM, DIOG and DIOF (Fig. 1) were isolated from DBT in our laboratory. Their chemical structures were determined by extensive spectroscopic analyses. ${ }^{\mathbf{9 1 3 , 2 8 , 2 9}}$ The purity of each compound was more than $98 \%$, by normalization of the peak area detected by UPLC analysis. Dimethyl sulfoxide (DMSO) was purchased from Sigma-Aldrich (St. Louis, MO, USA). HPLC grade acetonitrile, methanol and formic acid were purchased from ROE (Newark, NJ, USA). Deionized water $\left(18 \mathrm{M} \Omega \mathrm{cm}^{-1}\right)$ was prepared by distilled water through a Milli-Q system (Millipore, Milford, MA, USA). Other reagents and solvents were of analytical grade.

\section{Chromatographic and mass spectrometric conditions}

Chromatographic analysis was performed on an Agilent series 1290 UPLC system equipped with a quaternary pump, a degasser, an autosampler and a thermostated column compartment (Agilent Technologies, Palo Alto, CA, USA). Chromatographic separation was carried out at $30{ }^{\circ} \mathrm{C}$ on an Agilent Zorbax SB-C18 analytical column (4.6 mm i.d. $\times 50 \mathrm{~mm}, 1.8 \mu \mathrm{m}$, Agilent Technologies, Palo Alto, CA, USA). The mobile phase was a mixture of $0.1 \%$ formic acid in water (A) and acetonitrile (B) with a gradient elution as follows: $5-95 \% \mathrm{~B}$ at $0-20 \mathrm{~min}$. The flow rate was $0.4 \mathrm{~mL} \mathrm{~min}^{-1}$, and the column temperature was set at $30{ }^{\circ} \mathrm{C}$.
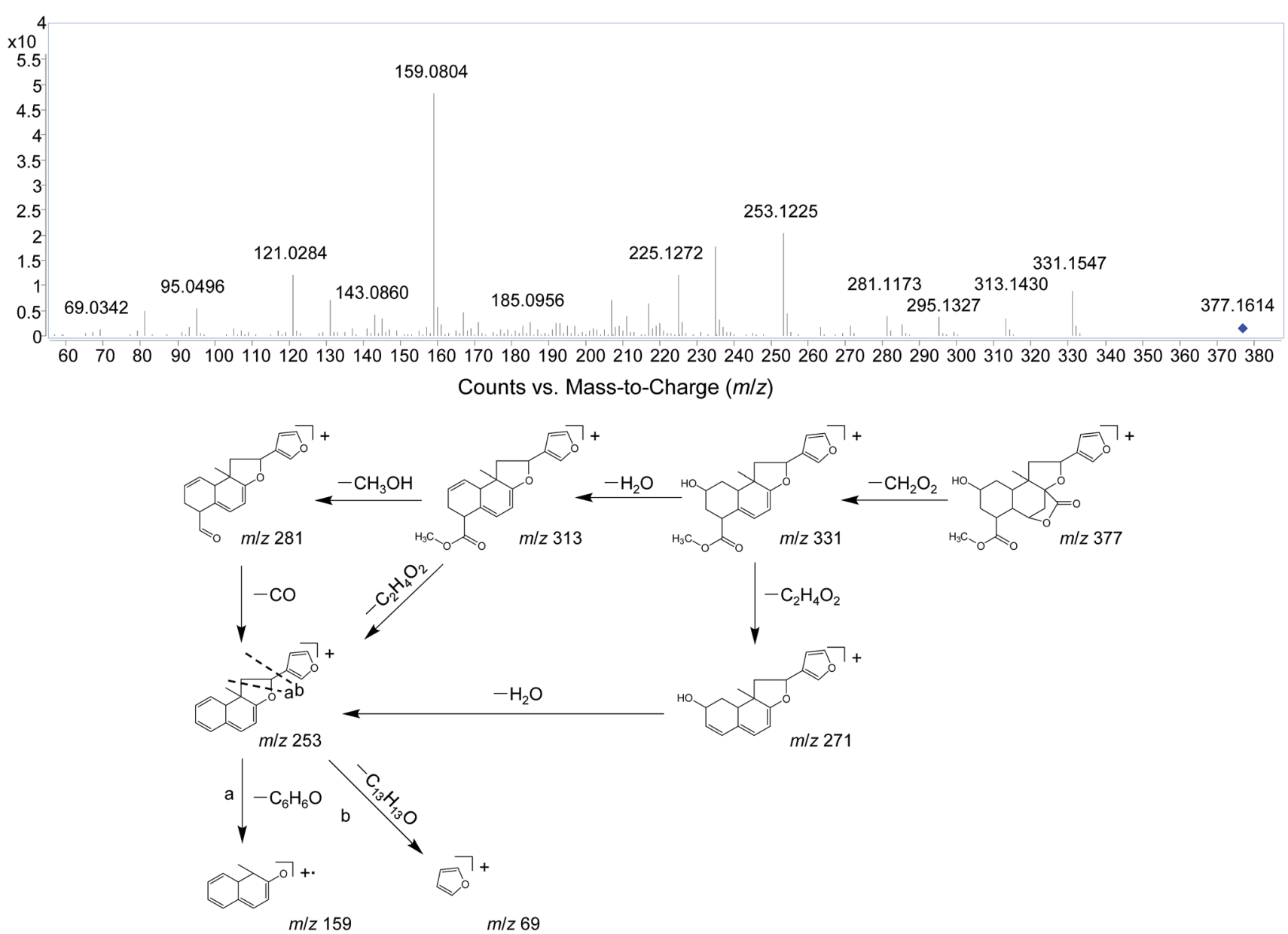

Fig. 2 The positive MS/MS spectra and proposed fragmentation pathways of DIOA. 
The mass spectrometric analysis was performed on a 6545 QTOF mass spectrometer (Agilent Technologies, Santa Clara, CA, USA) equipped with electrospray ionization source in positive mode. The mass spectrometric conditions were as follows: nebulizer pressure, $35 \mathrm{psi}$; capillary voltage, $3500 \mathrm{~V}$; fragmentor voltage, $135 \mathrm{~V}$; drying gas flow, $10 \mathrm{~L} \mathrm{~min}^{-1}$; drying gas temperature, $350{ }^{\circ} \mathrm{C}$; sheath gas flow, $11 \mathrm{~L} \mathrm{~min}^{-1}$; sheath gas temperature, $350{ }^{\circ} \mathrm{C}$. The mass rang was recorded from $\mathrm{m} / \mathrm{z} 50$ to $1500 \mathrm{Da}$. Data acquisition was performed with MassHunter Workstation (Agilent Technologies, Palo Alto, CA, USA). The TOF mass spectrometer was calibrated every day before sample analysis using reference masses at $\mathrm{m} / \mathrm{z} 121.0508$ and 922.0098.

\section{Animal experiments}

Male adult zebrafish (AB strain; 5 month old; weight, 0.4-0.5 g) were supplied by Nanjing Ezerinka Biotechnology Co., Ltd (Nanjing, China), and acclimatized to tap water in a glass aquarium for at least $10 \mathrm{~d}$ preceding experimentation. Fish were cultured at $25 \pm 1{ }^{\circ} \mathrm{C}$ in a $12 \mathrm{~h}: 12 \mathrm{~h}$ day/night cycle. The fish were fed daily during the acclimatization period, and were fasted $12 \mathrm{~h}$ before the day of the experiment. Animal studies were conducted in accordance with the Provision and General Recommendation of Chinese Experimental Animals Administration Legislation and were approved by Department of Science and Technology of Jiangsu Province (License number: SYXK (SU) 2016-0011).

\section{Drug administration and sample collection}

Zebrafish were randomly separated into six groups with six fish in each group. After fasting for $12 \mathrm{~h}$, the fish was kept individually in brown glass bottles maintaining at a temperature of 25 $\pm 1{ }^{\circ} \mathrm{C}$ in a water bath with $40 \mathrm{~mL}$ solution: one blank control group was exposed to $0.5 \%$ DMSO purified water (blank zebrafish group), and five groups were exposed to $40 \mathrm{~mL}$ solution of
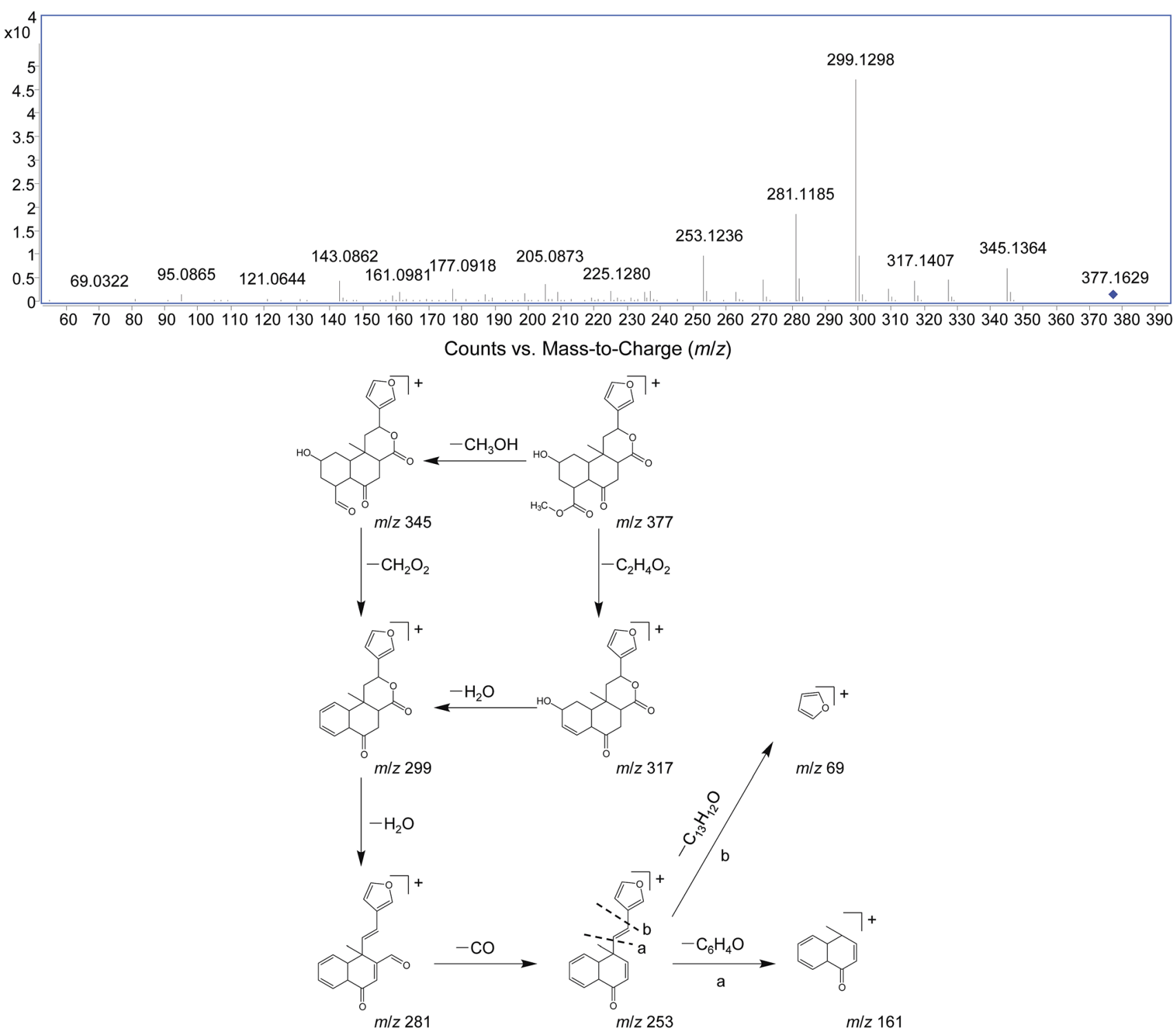

Fig. 3 The positive MS/MS spectra and proposed fragmentation pathways of DIOF. 
DIOA $\left(15.41 \mu \mathrm{g} \mathrm{mL} \mathrm{m}^{-1}\right)$, DIOC $\left(17.03 \mu \mathrm{g} \mathrm{mL}^{-1}\right)$, DIOG $(17.08 \mu \mathrm{g}$ $\left.\mathrm{mL}^{-1}\right)$, DIOM $\left(16.74 \mu \mathrm{g} \mathrm{mL}^{-1}\right.$ ) or DIOF $\left(16.55 \mu \mathrm{g} \mathrm{mL}{ }^{-1}\right)$ in $0.5 \%$ DMSO purified water (drug-treated groups). Zebrafish body and the solution were sampled at $24 \mathrm{~h}$. The zebrafish bodies of each group were combined and washed quickly with purified water three times, then weighed after sacrifice and removal of fins and scales of fish and stored at $-80^{\circ} \mathrm{C}$ until analysis; the solution of each group were also combined. The combined solutions of each group were sampled and also stored at $-80{ }^{\circ} \mathrm{C}$ until analysis.

\section{Sample preparation}

The aqueous solution ( $40 \mathrm{~mL}$ ) was freeze-dried to dryness, and the residue dissolved in $90 \%(\mathrm{v} / \mathrm{v})$ methanol $(1 \mathrm{~mL})$. The solution was filtered through a $0.22 \mu \mathrm{m}$ filter and $2 \mu \mathrm{L}$ was injected into the UHPLC-QTOF MS system for analysis. The zebrafish samples were cut with scissors, and $1 \mathrm{~g}$ was sampled and homogenized with physiological saline $(5 \mathrm{~mL})$, followed by centrifugation at $3500 \mathrm{rpm}$ for $15 \mathrm{~min}$, then the supernatant was mixed by vortexing with methanol at the ratio of $1: 4(\mathrm{v} / \mathrm{v})$ three times, followed by centrifugation at $3500 \mathrm{rpm}$ for $15 \mathrm{~min}$. The supernatant was evaporated to dryness with nitrogen at room temperature, and the residue was dissolved in $90 \%$ methanol $(1 \mathrm{~mL})$. After filtering through a $0.22 \mu \mathrm{m}$ filter, $2 \mu \mathrm{L}$ of the solution containing $1 \mathrm{~g}$ fish tissue per $\mathrm{mL}$ was injected into the UHPLC-QTOF MS system for analysis.

\section{Results and discussion}

\section{Mass spectrometric behaviors of DLs}

Several studies have confirmed that the mass fragmentation patterns of metabolites are similar to the parent compound, therefore the analysis of fragmentation pattern of parent compound is very important for the metabolite characterizations. ${ }^{30}$ In the present study, the mass spectrometric behaviors and fragmentation patterns of the DLs were investigated firstly. It was noted that the response of ESI (+) mode was much higher than that of ESI $(-)$ mode, therefore the positive mode was employed for the rest of the study.

DIOA provided a protonated molecule $[\mathrm{M}+\mathrm{H}]^{+}$and sodium adduct ion $[\mathrm{M}+\mathrm{Na}]^{+}$at $\mathrm{m} / \mathrm{z} 377$ and 399 , respectively. The product ion at $\mathrm{m} / \mathrm{z} 69$ was generated from the furan moiety. Additionally, the mass spectrum showed major fragment ions at $m / z \quad 159\left(\mathrm{C}_{11} \mathrm{H}_{11} \mathrm{O}\right), 253\left(\mathrm{C}_{17} \mathrm{H}_{17} \mathrm{O}_{2}\right), 271\left(\mathrm{C}_{17} \mathrm{H}_{19} \mathrm{O}_{3}\right), 281$ $\left(\mathrm{C}_{18} \mathrm{H}_{17} \mathrm{O}_{3}\right), 295\left(\mathrm{C}_{19} \mathrm{H}_{19} \mathrm{O}_{3}\right), 313\left(\mathrm{C}_{19} \mathrm{H}_{21} \mathrm{O}_{4}\right)$ and $331\left(\mathrm{C}_{19} \mathrm{H}_{23} \mathrm{O}_{5}\right)$. The product ion spectrum of DIOA under high collision energy scan and the fragmentation pathways of DIOA are proposed in Fig. 2. DIOC provided a protonated molecule $[\mathrm{M}+\mathrm{H}]^{+}$and the ammonium adduction ion $\left[\mathrm{M}+\mathrm{NH}_{4}\right]^{+}$at $\mathrm{m} / z 363$ and 380, respectively. The mass spectrum showed major fragment ions at $m / z \quad 159\left(\mathrm{C}_{11} \mathrm{H}_{11} \mathrm{O}\right), 253\left(\mathrm{C}_{17} \mathrm{H}_{17} \mathrm{O}_{2}\right), 271\left(\mathrm{C}_{17} \mathrm{H}_{19} \mathrm{O}_{3}\right), 281$ $\left(\mathrm{C}_{18} \mathrm{H}_{17} \mathrm{O}_{3}\right), 299\left(\mathrm{C}_{18} \mathrm{H}_{19} \mathrm{O}_{4}\right)$ and $317\left(\mathrm{C}_{18} \mathrm{H}_{21} \mathrm{O}_{5}\right)$ (Fig. $\left.\mathrm{S} 1 \dagger\right)$. As expected, these observations clearly demonstrated that DIOA and DIOC shared the same fragment ions and fragmentation pathways due to their similar chemical skeleton.

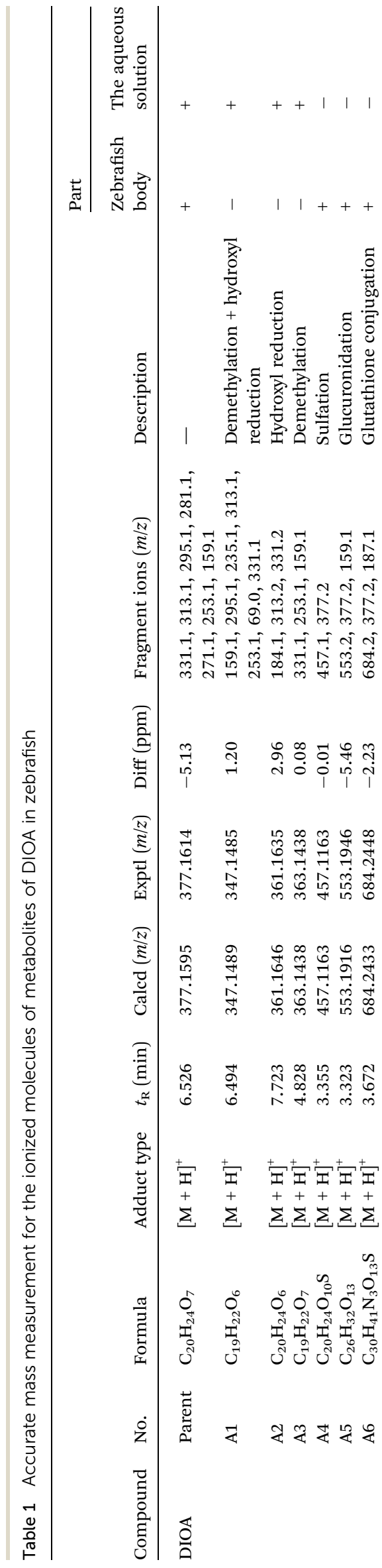


त)

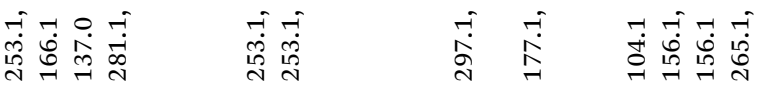
ma ma

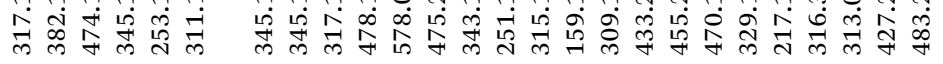

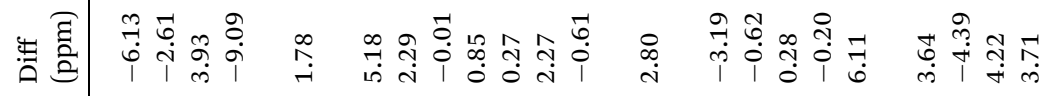

蒙营

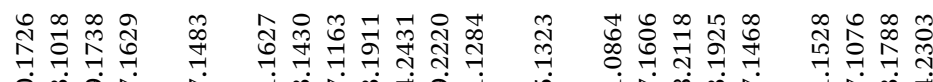

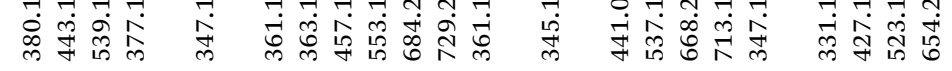

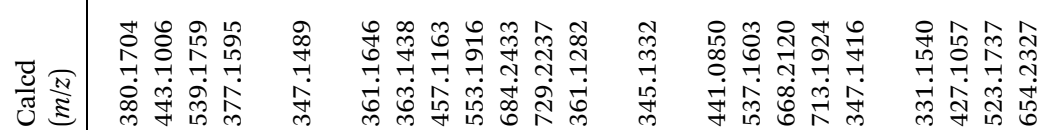

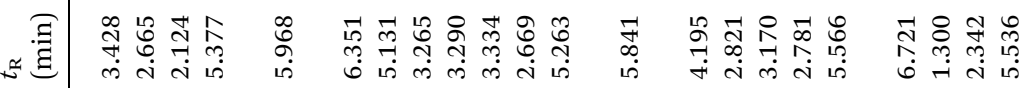

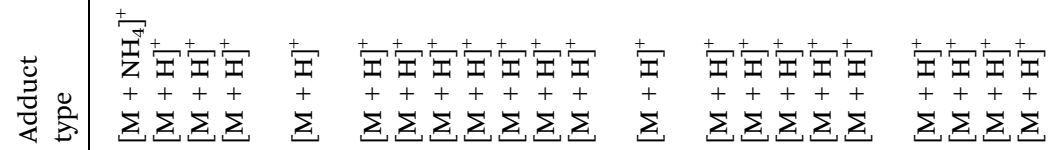

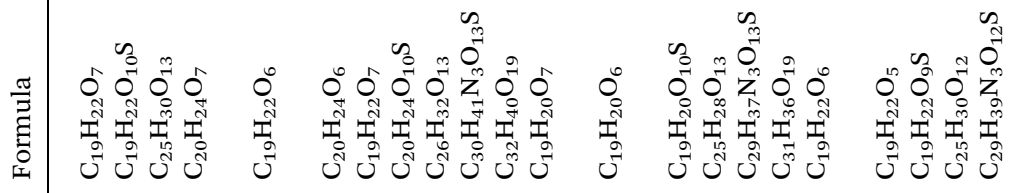

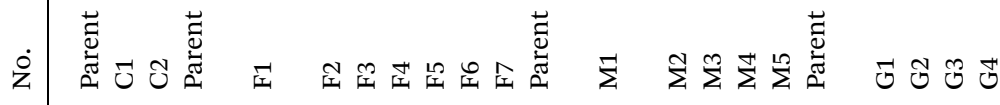
¿্:

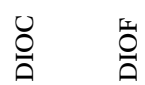

$\stackrel{\sum}{\varrho}$ 
DIOF showed $[\mathrm{M}+\mathrm{H}]^{+}$ion at $m / z 377.1629$ in positive mode, corresponding to the molecular formula $\mathrm{C}_{20} \mathrm{H}_{24} \mathrm{O}_{7}$. The neutral loss of 60 Da generated from ion at $\mathrm{m} / \mathrm{z} 377$ to 317 ; suggested the presence of a terminal acetic acid unit (Fig. 3). Apart from the characteristic ions at $m / z 281,271$, and 253 which were also found in DIOA and DIOC, the predominant ion at $m / z 345(-32$ Da) was supposed to be formed by a neutral loss of $\mathrm{CH}_{3} \mathrm{OH}$ at the position of ester group.

DIOM provided a protonated molecule $[\mathrm{M}+\mathrm{H}]^{+}$and the ammonium adduction ion $\left[\mathrm{M}+\mathrm{NH}_{4}\right]^{+}$at $\mathrm{m} / z \quad 361$ and 378 , respectively. DIOM exhibited a series of fragmentation ions at $\mathrm{m} / \mathrm{z} 159,251,297,315,333$ and 343 , and the specific ion at $\mathrm{m} / \mathrm{z}$ 69 corresponded to furan group. For better understanding of fragmentation pathway of DIOM, the fragmentation behaviors are given in Fig. S2. $\dagger$

DIOG gave precursor ion $[\mathrm{M}+\mathrm{H}]^{+}$at $m / z 347.1468$ (with $6.11 \mathrm{ppm}$ error compared with theoretically calculated value) in positive mode, suggesting the molecular formula $\mathrm{C}_{19} \mathrm{H}_{22} \mathrm{O}_{6}$. In the MS/MS spectra, the parent compound gave a series of fragmentation ions at $m / z 145,217,237,265,283,311$ and 329. The fragmentation pathways of DIOG were proposed in Fig. S3. $\dagger$

The fragment ion of the furan ring at $\mathrm{m} / \mathrm{z} 69$ presented in the MS/MS spectra of all these DLs. The characteristic neutral losses and product ions from the parent compounds could be used to identify the metabolites formed in vivo from DIOA, DIOC, DIOF, DIOG and DIOM.

\section{Structure elucidation of DLs metabolites in zebrafish}

As the core of the present study, metabolites of the DLs in zebrafish were identified using UHPLC-QTOF MS by matching accurate masses. After comparing the results of drug samples with the corresponding blank samples, a total of 6, 2, 7, 5 and 4 metabolites of DIOA, DIOC, DIOF, DIOM and DIOG were detected and identified in the zebrafish body and the aqueous solution, respectively. The chromatographic retention times and mass spectrometric data of the parent compounds and metabolites were listed in Tables 1, 2. In addition, the proposed metabolic pathways of the five analytes in zebrafish were depicted in Fig. 4 (DIOA), Fig. 5 (DIOF), Fig. S4† (DIOC), Fig. S5† (DIOG) and Fig. S6† (DIOM), respectively.

\section{Metabolites of DIOA}

DIOA, exhibited the protonated molecular ion at 377.1614 in positive mode, was confirmed by a general analysis of the MS and MS/MS fragmentation behaviors and retention time. The parent component was identified and detected in both zebrafish body and the aqueous solution after the metabolism for $24 \mathrm{~h}$.

The metabolite named as A1 was observed as a protonated molecule $[\mathrm{M}+\mathrm{H}]^{+}$at $m / z 347.1485$, with a retention time of $6.49 \mathrm{~min}$. The relative abundant fragment ion at $\mathrm{m} / \mathrm{z} 331$ was 16 Da less than that of the parent ion, suggesting the existence of an oxygen-containing group. The characteristics of other

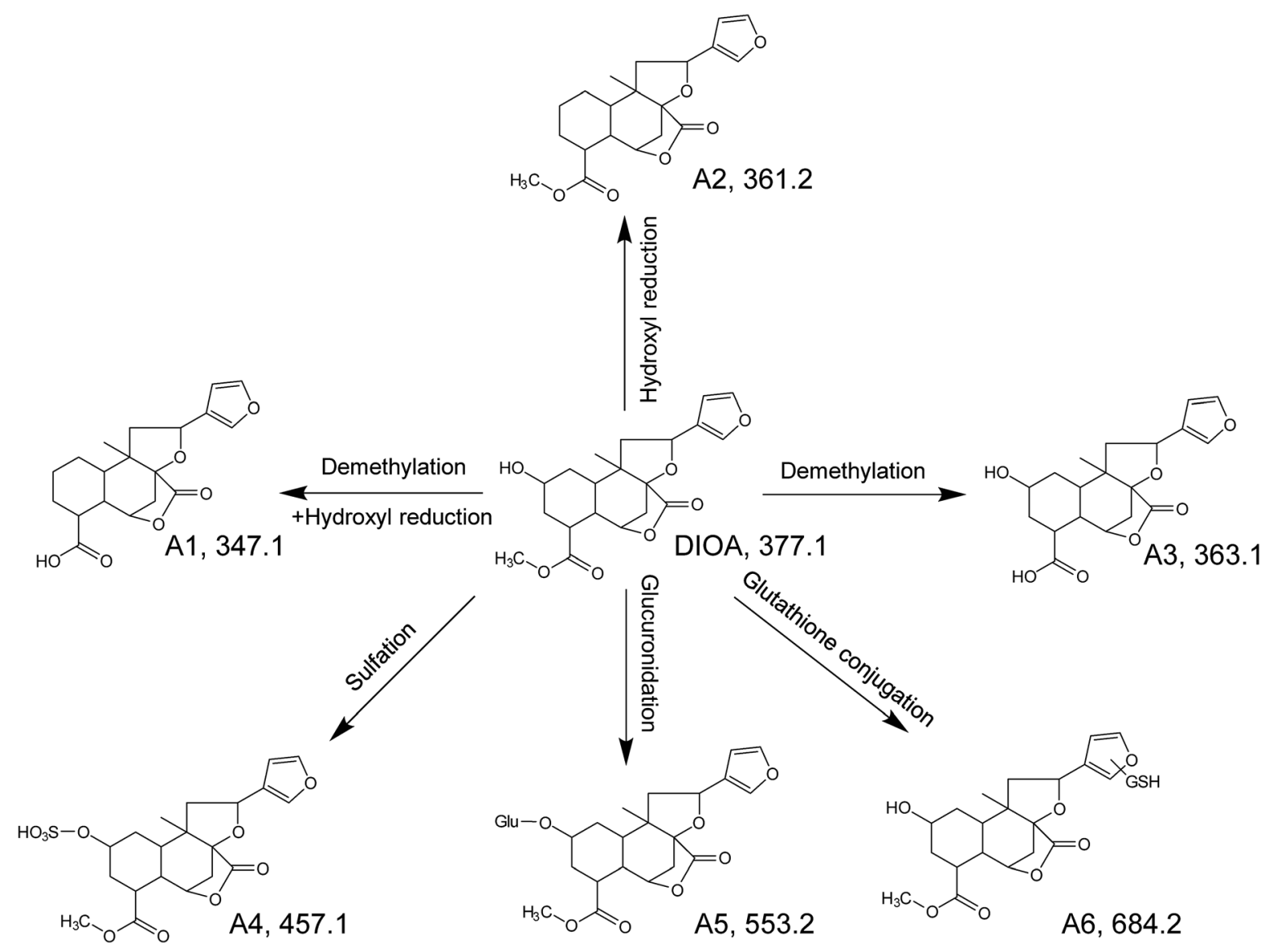

Fig. 4 The proposed metabolic pathways of DIOA in zebrafish. 


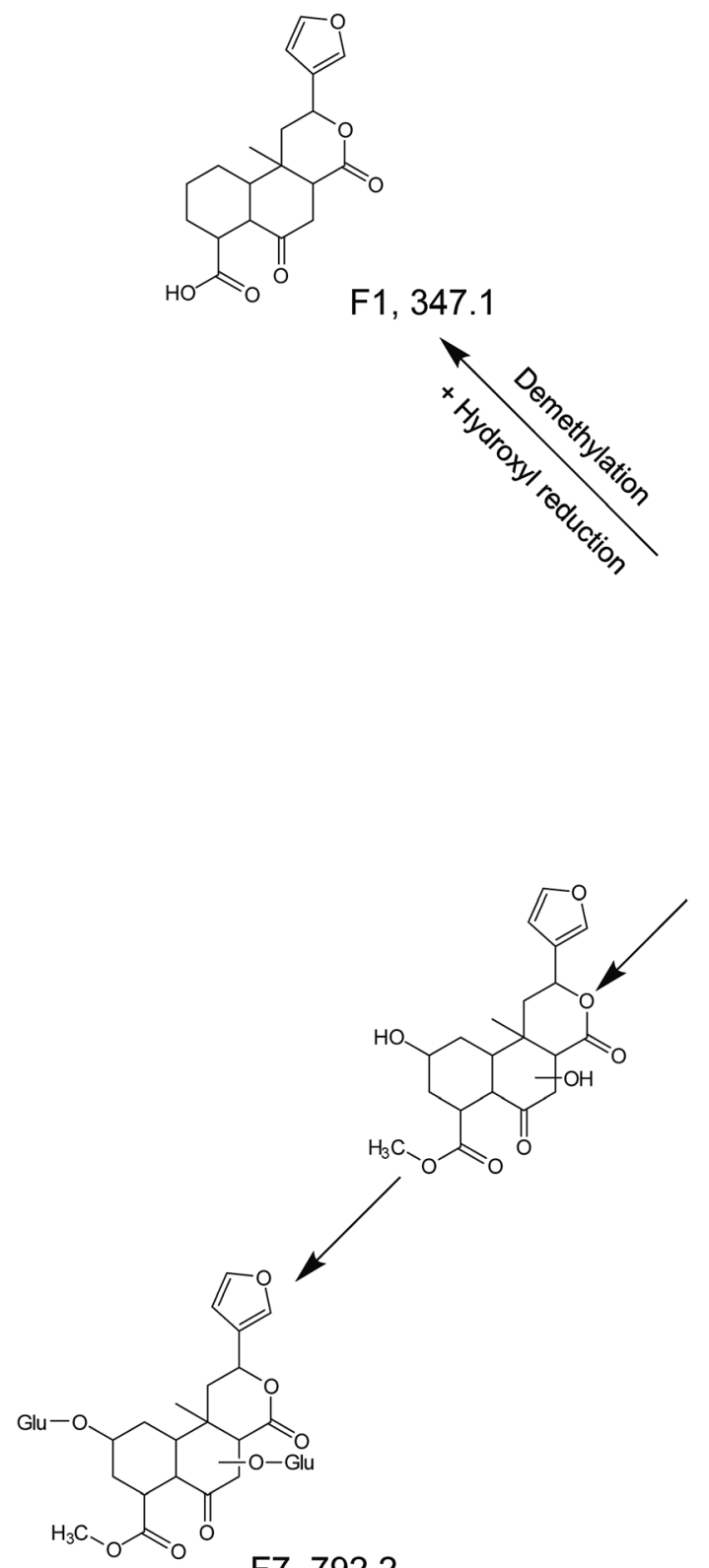<smiles>COC(=O)C1CCCC2CC3C(=O)OC(c4ccoc4)CC3C(=O)CC21</smiles>

F2, 361.1<smiles>CC12CC(c3ccoc3)OC(=O)C1CC(=O)C1C(C(=O)O)CC(O)CC12C</smiles>

F3, 363.1
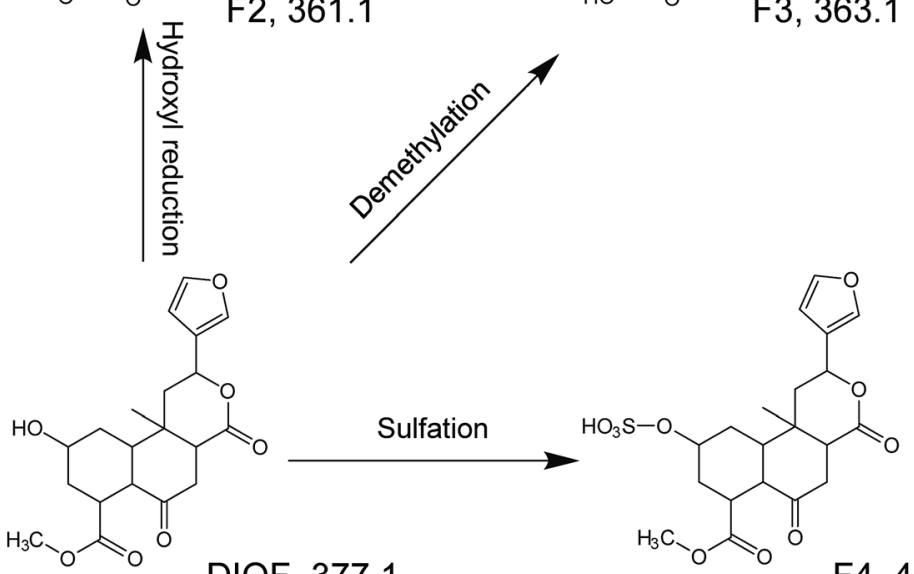

DIOF, 377.1

$\mathrm{F} 4,457.1$

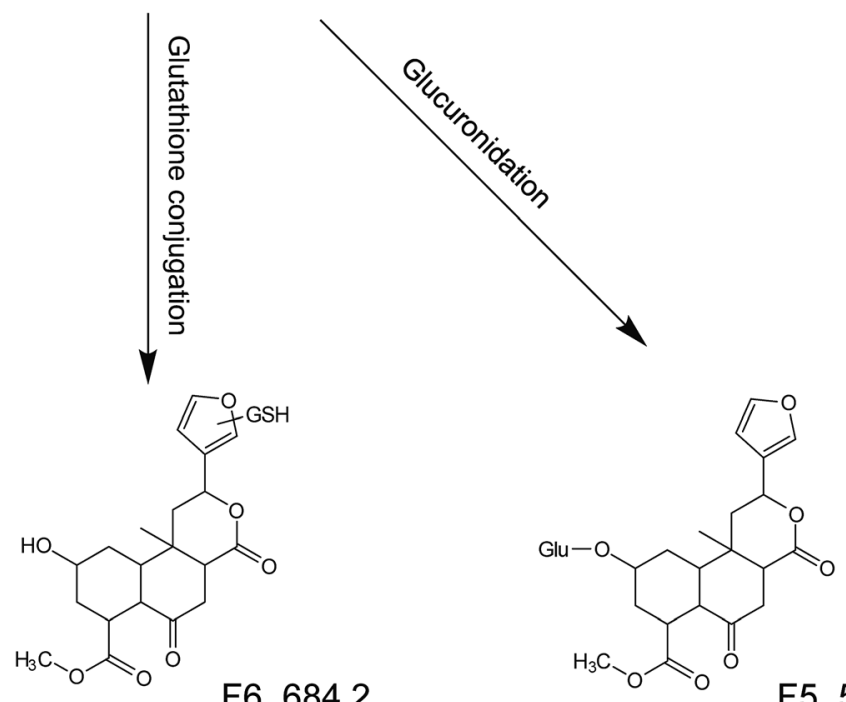

$\mathrm{F} 6,684.2$

$F 5,553.2$

Fig. 5 The proposed metabolic pathways of DIOF in zebrafish.

fragments observed at $m / z 313\left(\left[\mathrm{M}+\mathrm{H}-\mathrm{O}-\mathrm{H}_{2} \mathrm{O}\right]^{+}\right), 295([\mathrm{M}+\mathrm{H}-$ $\left.\left.\mathrm{O}-2 \mathrm{H}_{2} \mathrm{O}\right]^{+}\right), 253\left(\left[\mathrm{M}+\mathrm{H}-\mathrm{O}-\mathrm{H}_{2} \mathrm{O}-\mathrm{CH}_{3} \mathrm{OH}-\mathrm{CO}\right]^{+}\right), 235([\mathrm{M}+\mathrm{H}-\mathrm{O}-$ $\left.\left.2 \mathrm{H}_{2} \mathrm{O}-\mathrm{CH}_{3} \mathrm{OH}-\mathrm{CO}\right]^{+}\right)$and $159\left(\left[\mathrm{M}+\mathrm{H}-\mathrm{O}-\mathrm{H}_{2} \mathrm{O}-\mathrm{CH}_{3} \mathrm{OH}-\mathrm{CO}-\right.\right.$ $\left.\mathrm{C}_{6} \mathrm{H}_{6} \mathrm{O}\right]^{+}$), which shared the same fragmentation pattern as DIOA.

A2, eluted at $7.72 \mathrm{~min}$, was characterized as the main metabolite, with the predominant quasi-molecular ion $[\mathrm{M}+\mathrm{H}]^{+}$ at $m / z 361.1635$, which was 16 Da less than that of DIOA, suggesting a dehydration followed by reduction.

$\mathrm{A} 3$, eluted at $4.80 \mathrm{~min}$, was observed as a protonated molecule $[\mathrm{M}+\mathrm{H}]^{+}$at $m / z$ 363.1438, which was 14 Da less than DIOA, suggesting a methyl ester of carboxylic acid in the side chain. The characteristics of other fragments observed at $\mathrm{m} / \mathrm{z} 331.1984$ $\left([\mathrm{M}+\mathrm{H}-2 \mathrm{O}]^{+}\right)$, and $159\left(\left[\mathrm{M}+\mathrm{H}-2 \mathrm{O}-\mathrm{H}_{2} \mathrm{O}-\mathrm{CH}_{3} \mathrm{OH}-\mathrm{CO}-\mathrm{C}_{6} \mathrm{H}_{6} \mathrm{O}\right]^{+}\right)$.
The mass fragment of $m / z 159.0807$ was consistent with the fragmentation pattern of DIOA.

A4, eluted at $3.36 \mathrm{~min}$, was characterized as the main metabolite, with the predominant quasi-molecular ion $[\mathrm{M}+\mathrm{H}]^{+}$ at $m / z 457.1163\left(\mathrm{C}_{20} \mathrm{H}_{24} \mathrm{O}_{10} \mathrm{~S}\right)$, which generated a fragment ion at $\mathrm{m} / z 377$ corresponding to the neutral loss of $80 \mathrm{Da}\left(\mathrm{SO}_{3}\right)$, suggesting that A4 were deduced as DIOA sulfate conjugate. Similarly, A5 was observed as a protonated molecule $[\mathrm{M}+\mathrm{H}]^{+}$at $\mathrm{m} / \mathrm{z}$ 553.1946 , with a retention time of $3.32 \mathrm{~min}$. The product ion at $\mathrm{m} / \mathrm{z} 377$ was corresponding to a neutral loss of $176 \mathrm{Da}\left(\mathrm{C}_{6} \mathrm{H}_{8} \mathrm{O}_{6}\right)$ from the parent $[\mathrm{M}+\mathrm{H}]^{+}$ion. Further analysis of A5 by UHPLCQTOF MS demonstrated its protonated molecular ion $[\mathrm{M}+\mathrm{H}]^{+}$ at $\mathrm{m} / \mathrm{z} 159.0893$ in positive ion mode, which matched the elemental composition of DIOA. Therefore, A5 was tentatively identified the glucuronidated metabolite of the DIOA. 
A6, eluted at $3.67 \mathrm{~min}$, was characterized as the main metabolite, with the predominant quasi-molecular ion $[\mathrm{M}+\mathrm{H}]^{+}$ at $m / z 684.2448$. The product ion at $m / z 377$ was derived from the loss of GSH moiety ( $-307 \mathrm{Da}$ ) from $m / z 684$. This indicated that the participation of GSH in the formation of A6.

\section{Metabolites of DIOC/DIOF/DIOM/DIOG}

In all, two metabolites (C1-C2) of DIOC, seven metabolites (F1F7) of DIOF, five metabolites (M1-M5) of DIOM and four metabolites (G1-G4) of DIOG were tentatively characterized by MS and MS/MS in the zebrafish body and the aqueous solution, respectively. All metabolites were detected and characterized based on the accurate mass measurement, the fragmentation pattern of the parent compounds and relevant drug biotransformation knowledge.

Like mammals, the zebrafish has a serious of drugmetabolizing enzymes, such as CYP450 isoforms or conjugation enzymes including glutathione- $S$-transferase, uridine diphosphoglucuronyl transferases, and sulfotransferases. ${ }^{31-34}$ The xenobiotic metabolism is often divided into two phases: modification (phase-I) and conjugation (phase-II). ${ }^{23}$ CYP450, belonging to monoxygenases, is the prevailing group of phase I enzymes. ${ }^{35-37}$ The present study showed that, after $24 \mathrm{~h}$ metabolism, the phase-I metabolites (such as A1/A2/A3) were detected in the solution sample of zebrafish. In subsequent phase-II reactions, these activated xenobiotic metabolites are prone to be conjugated with charged species such as glutathione (GSH), sulfate, glycine, or glucuronic acid. ${ }^{38,39}$ The obtained results indicated that sulfation, glucuronidation and glutathione conjugations (such as A4/A5/A6) were the main physiological process of metabolism of the DLs. It should be noted that the GSH conjugate was found in zebrafish body after metabolism, which facilitate the metabolic investigation of DB and EEA in rats.

Structurally, unlike DB and EEA, these DLs have a hydroxyl group, which might lead to distinction of solubility and metabolism between DLs. The sulfation, and glucuronidation, along with hydroxyl reduction products were detected and identified. Additionally, fewer phase-I metabolites were detected and identified in DIOC-treated group compared with the zebrafish given DIOA, which might partly be related to the solubility difference between the two DLs. Overall, the results indicated that the hydroxyl group possibly plays an essential role in the metabolism of the DLs.

\section{Conclusions}

In our study, an UHPLC-QTOF MS method was successfully applied for the analysis of the metabolites of five DLs in zebrafish. The main phase-I and phase-II metabolites, including hydroxyl reduction metabolites, sulfate conjugated metabolites, glutathione adducts and glucuronic acid conjugated metabolites, were detected and identified on the basis of the mass-to-charge ratios and fragments. The investigation confirmed that the reaction pathways for degradation of DLs in zebrafish involving hydroxyl reduction, glucuronidation, glutathione conjugation and sulfation. Toxic effects of compounds in an organism are substantially dependent on their metabolites. The metabolites observed in zebrafish, which will be greatly helpful in elucidating the potential toxic effects of DLs in DBT.

\section{Conflicts of interest}

The authors declare no competing financial interests.

\section{Acknowledgements}

This work was supported by the National Natural Science Foundation of China (No. 81773993 and 81573833), the Natural Science Foundation of Jiangsu Province (No. BK20151442) and the Project Funded by the Priority Academic Program Development (PAPD) of Jiangsu Higher Education Institutions.

\section{References}

1 F. M. Niyas, Res. J. Pharm. Technol., 2015, 8, 1059-1062.

2 Y. X. Tang, China J. Chin. Mater. Med., 1995, 20, 435-438.

3 T. Natascha, P. Iffat and A. K. Ikhlas, Genome, 2016, 60, 201207.

4 W. J. Lee, H. W. Kim, H. Y. Lee and C. G. Son, Food Chem. Toxicol., 2015, 84, 47-54.

5 H. Yang, J. X. Li, X. Q. Cui, C. Yang, L. Y. Li, J. L. Liu, L. C. Mu, J. C. Yuan and B. Zhang, Clin. Misdiagn. Misther., 2006, 19, 85-87.

6 J. M. Wang, L. L. Ji, H. Liu and Z. T. Wang, BioSci. Trends, 2010, 4, 79-85.

7 H. Y. Gao, A. L. Shui, Y. H. Chen, X. Y. Zhang and L. J. Wu, J. Shenyang Pharm. Univ., 2003, 20, 178-180.

8 S. Ghosh, V. S. Parihar, P. More, D. D. Dhavale and B. A. Chopade, Med. Chem., 2014, 5, 160-172.

9 H. Liu, G. X. Chou, Y. L. Guo, L. L. Ji, J. M. Wang and Z. T. Wang, Phytochemistry, 2010, 71, 1174-1180.

10 G. Wang, J. S. Liu, B. B. Lin, G. K. Wang and J. K. Liu, Chem. Pharm. Bull., 2009, 57, 625-627.

11 T. Kawasaki, T. Komori and S. Setoguchi, Chem. Pharm. Bull., 1968, 16, 2430-2435.

12 Y. Tang, Y. B. Xue, L. Zhou, J. W. Zhang, G. M. Yao, Z. W. Luo, G. Du and Y. H. Zhang, Chem. Pharm. Bull., 2014, 62, 719724.

13 Y. Ida, S. Kubo, M. Fujita, T. Komori and T. Kawasaki, Justus Liebigs Ann. Chem., 1978, 818-833.

14 B. H. Yang, W. Liu, K. X. Chen, Z. T. Wang and C. H. Wang, Drug Metab. Dispos., 2014, 42, 1737-1750.

15 D. J. Lin, C. Y. Li, Y. Peng, H. Y. Gao and J. Zheng, Drug Metab. Dispos., 2014, 42, 1727-1736.

16 W. W. Li, D. J. Lin, H. Y. Gao, Y. J. Xu, D. Y. Meng, C. V. Smith, Y. Peng and J. Zheng, Arch. Toxicol., 2016, 90, 863-872.

17 D. J. Lin, W. W. Li, Y. Peng, C. F. Jiang, Y. J. Xu, H. Y. Gao and J. Zheng, Chem. Res. Toxicol., 2016, 29, 359-366.

18 C. Y. Li, D. J. Lin, H. Y. Gao, H. M. Hua, Y. Peng and J. Zheng, Chem. Res. Toxicol., 2015, 28, 384-393. 
19 D. J. Lin, X. C. Guo, H. Y. Gao, L. Cheng, M. S. Cheng, S. J. Song, Y. Peng and J. Zheng, Chem. Res. Toxicol., 2015, 28, 1737-1746.

20 L. Guo, L. Duan, X. Dong, L. L. Dou, P. Zhou, P. Li and E. H. Liu, J. Pharm. Biomed. Anal., 2015, 107, 473-479.

21 R. Xing, L. J. Zhou, L. Xie, K. Hao, T. Rao, Q. Wang, W. Ye, H. Fu, X. W. Wang, G. J. Wang and Y. Liang, Anal. Chim. Acta, 2015, 867, 56-66.

22 R. D. Arnold, J. E. Slack and R. M. Straubinger, J. Chromatogr. $B, 2004,808,141-152$.

23 Y. J. Wei, P. Li, H. W. Fan, Y. R. Peng, W. Liu, C. M. Wang, L. Shu and X. B. Jia, Molecules, 2011, 16, 6621-6633.

24 Y. J. Wei, P. Li, C. M. Wang, Y. R. Peng, L. Shu, X. B. Jia, W. Q. Ma and B. Wang, Molecules, 2012, 17, 8617-8632.

25 B. Chen, J. Y. Wei, D. Wang and B. X. Jia, Arch. Pharmacal Res., 2014, 38, 1468-1476.

26 G. W. Wang, Z. K. Du, H. Y. Chen, Y. Su, S. X. Gao and L. Mao, Environ. Sci. Technol., 2016, 50, 13555-13564.

27 Y. J. Wei, Q. Ning, X. B. Jia and Z. A. Gong, Arch. Pharmacal Res., 2009, 40, 1009-1011.

28 A. Lentini, J. Webster, B. Ternai and T. Komori, Magn. Reson. Chem., 1986, 24, 646-648.

29 R. B. Teponno, A. L. Tapondjou, E. Abou-Mansour, H. Stoeckli-Evans, P. Tane and L. Barboni, Phytochemistry, 2008, 69, 2374-2379.
30 L. Wang, H. Ye, D. Sun, T. Meng, L. Cao, M. Wu, M. Zhao, Y. Wang, B. Chen, X. Xu, G. Wang and H. Hao, Anal. Chem., 2017, 89, 1229-1237.

31 L. M. Félix, A. M. Vidal, C. Serafim, A. M. Valentim, L. M. Antunes, S. Campos, M. Matos, S. M. Monteiro and A. M. Coimbra, RSC Adv., 2016, 6, 61254-61266.

32 A. Tierbach, K. J. Groh, R. Schonenberger, K. Schirmer and M. J. Suter, Toxicol. Sci., 2018, DOI: 10.1093/toxsci/kfx293.

33 M. Dong, L. S. Zhu, B. Shao, S. Y. Zhu, J. H. Wang, H. Xie, J. H. Wang and F. H. Wang, Ecotoxicol. Environ. Saf., 2013, 92, 1-9.

34 M. L. Scornaienchi, C. Thornton, K. L. Willett and J. Y. Wilson, Arch. Biochem. Biophys., 2010, 502, 17-22.

35 H. P. Song, H. Zhang, Y. Fu, H. Y. Mo, M. Zhang, J. Chen and P. Li, J. Chromatogr. B, 2014, 961, 56-61.

36 G. W. Wang, H. Y. Chen, Z. K. Du, J. H. Li, Z. Y. Wang and S. X. Gao, Sci. Total Environ., 2017, 590-591, 50-59.

37 H. P. Song, J. Chen, J. Y. Hong, H. Hao, L. W. Qi, J. Lu, Y. Fu, B. Wu, H. Yang and P. Li, Chem. Commun., 2015, 51, 14941497.

38 J. Petra and M. Šiller, InTech, 2012, 35-60.

39 Y. X. Wang, H. P. Hao, G. J. Wang, P. F. Tu, Y. Jiang, Y. Liang, L. Dai, H. Yang, L. Lai and C. N. Zheng, Talanta, 2009, 80, 572-580. 